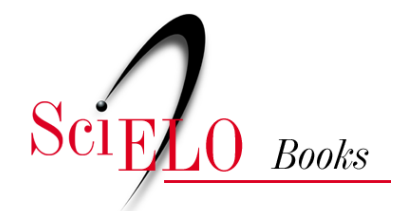

\title{
Parte III - Formação continuada de professores Capítulo 23. Formação de professores de geografia: trajetórias e desafios do Programa Institucional de Bolsa de Iniciação à Docência (PIBID)
}

\author{
Gilda Maria Cabral Benaduce \\ Lisane Regina Vidal Conceição
}

\section{SciELO Books / SciELO Livros / SciELO Libros}

BEMADUCE, G.M.C., and CONCEIÇÃO, L.R.V. Formação de professores de geografia: trajetórias e desafios do Programa Institucional de Bolsa de Iniciação à Docência (PIBID). In: DAVID, C., and CANCELIER, J.W., eds. Reflexões e práticas na formação de educadores [online]. Rio de Janeiro: EdUERJ, 2018, pp. 357-372. ISBN 978-85-7511-475-9.

https://doi.org/10.7476/9788575114759.0024.

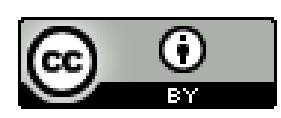

All the contents of this work, except where otherwise noted, is licensed under a Creative Commons Attribution 4.0 International license.

Todo o conteúdo deste trabalho, exceto quando houver ressalva, é publicado sob a licença Creative Commons Atribição $\underline{4.0}$.

Todo el contenido de esta obra, excepto donde se indique lo contrario, está bajo licencia de la licencia $\underline{\text { Creative Commons }}$ $\underline{\text { Reconocimento } 4.0 .}$. 


\section{Formação de professores de geografia}

\section{Trajetórias e desafios do Programa Institucional de Bolsa de Iniciação à Docência (PIBID)}

Gilda Maria Cabral Benaduce Lisane Regina Vidal Conceição

\section{Introdução}

O presente capítulo aborda o ensino e a formação de professores de Geografia, tendo como foco discussões que versam sobre as atividades docentes desenvolvidas por meio de um subprojeto da Geografia vinculado ao Programa Institucional de Bolsa de Iniciação à Docência (PIBID). Tais atividades são o fruto das reflexões compartilhadas entre os participantes do programa, professora coordenadora, professoras supervisoras e alunos bolsistas do curso de Geografia, ao longo da vigência do programa na Universidade Federal de Santa Maria (UFSM).

Nesse contexto, o presente artigo discute as concepções de conhecimento escolar e os desafios do programa para com a Geografia na escola, bem como as trajetórias traçadas pelos antigos bolsistas do programa. O desenvolvimento do trabalho deu-se mediante o estudo das atividades desenvolvidas nas escolas públicas e desafios contemporâneos enfrentados pelos antigos bolsistas em seu trabalho diário como docentes na escola. Para tal, foram aplicados questionários com antigos bolsistas de iniciação à docência do programa.

Compreende-se que, para muitas escolas públicas de ensino fundamental e médio, ainda é um desafio reconhecer e trabalhar com conhecimentos que sejam significativos para os educandos, cuja concepção do conhecimento tem oscilado entre perspectivas ainda conservadoras e perspectivas 
emancipatórias e críticas. Dessa forma, junto à escola, o PIBID busca desenvolver atividades que promovam aprendizagens significativas aos alunos por meio de práticas que, ao mesmo tempo, possibilitem novos aprendizados aos acadêmicos em formação, contribuindo para a formação docente, pois, conforme ressalta Callai (2013), o professor vai saber ensinar se ele aprendeu.

Portanto, acredita-se que a prática pedagógica proporcionada pelo PIBID seja fundamental para a formação de professores conhecedores da Geografia escolar.

\section{Iniciação à docência e seus saberes}

A formação de professores encontra no PIBID a possibilidade de vivenciar o diálogo entre a formação teórica oportunizada na universidade com aquela oportunizada pela escola, compondo, antes de tudo, uma postura de troca e não de sobreposição de saberes. A partir desse ponto de vista, entende-se que a escola e seus professores possuem experiências e saberes importantes a serem compartilhados com a universidade, que, por conseguinte, tem a necessidade de compartilhar suas pesquisas com a escola.

Nessa direção, o PIBID Geografia, em desenvolvimento na universidade, objetiva compreender as mudanças educacionais, que interferem no ensino de Geografia. Tais mudanças devem estar relacionadas às complexas transformações sociais que nem sempre são paralelas às mudanças educacionais, configurando um descompasso que acentua a necessidade de avaliar e monitorar essas situações. A investigação também é outro aspecto relevante, especialmente nas ações que retratam características da geografia tradicional escolar, para que esta possa ser superada e estendida ao cotidiano do educando.

É também relevante contribuir para o entendimento do mundo atual, que se dá pela apropriação do espaço pelos homens, da apropriação da natureza pelo homem e da organização do mundo, no que tange aos arranjos culturais, sociais e econômicos construídos historicamente. Pautada na realidade contemporânea, a Geografia é a ciência do presente, e seu estudo recai no espaço geográfico construído pelo homem e cuja visibilidade nunca foi tão explorada como nos dias atuais. 
A Geografia no ensino básico pressupõe ao educando a inserção das noções espaciais, em suas diversas escalas e configurações, oportunizando-lhe situações para lidar com as categorias espaço, natureza, paisagem, conexões com o mundo atual e com a sua realidade. É também relevante propiciar condições para a construção de competências, revelando o real, estabelecendo patamares em relação ao contexto espacial dos fenômenos que configuram cada sociedade com a própria realidade. Identificar o seu lugar no mundo permite que o educando seja mais problematizador que explicativo; sobre o espaço cotidiano, que ele seja mais crítico do que passivo; e, ao estabelecer comparações, contradições e desafios, que seja feito em nível local e global.

Nesse sentido, o projeto político-pedagógico do curso de Licenciatura em Geografia da UFSM pontua a formação acadêmica, cujos contornos asseguram leituras da realidade, por meio de elementos norteadores da organização curricular, na definição das competências e habilidades básicas a serem desenvolvidas no ensino, a partir dos referenciais propostos pelo conhecimento científico da Geografia.

No projeto PIBID/Geografia, tanto na edição de 2011 como em 2014, envolveram-se dez bolsistas, acadêmicos do curso de Licenciatura em Geografia, duas professoras de escola pública (supervisoras na escola), duas escolas públicas e um professor da Universidade (coordenador de área). O desenvolvimento do programa ocorre em duas escolas públicas de educação básica da cidade de Santa Maria, Escola Estadual de Ensino Médio Dom Antônio Reis e Instituto Estadual Luiz Guilherme do Prado Veppo, atendendo tanto ao Ensino Fundamental como ao Ensino Médio, respectivamente, ambas pertencentes ao estado do Rio Grande do Sul.

As dinâmicas propostas nesse projeto permitem que todos os bolsistas de graduação participem do cotidiano da escola pública, desenvolvendo atividades ligadas ao ensino/aprendizagem, elaborando questóes de pesquisa de forma integrada às demandas da escola. Na universidade, por sua vez, apresentam essas questões para discussão e debate em reuniões semanais.

Durante o acompanhamento do trabalho, a docência estrutura-se também como um campo de pesquisa, no sentido das possibilidades e dos desafios do cotidiano escolar, no qual é possível exercitar os princípios de uma educação libertadora, tomando-se, como ponto de partida para o trabalho, o diálogo entre estudantes e professores, entre os bolsistas do PIBID e seus coordenadores e supervisores, e entre os educandos da escola pública e os bolsistas do PIBID. 
As atividades em sala de aula envolvem desde a busca pelo conteúdo programático desenvolvido, assuntos de interesse dos educandos, até os temas e estudos a serem realizados pelos bolsistas. Essa seleção dá-se coletivamente, tendo como base teórico-metodológica aqueles educadores que priorizam mais o processo de aprendizagem do que propriamente o conteúdo. Freire (1972) exige uma nova educação expressa em uma nova escola, voltada à fomentação de perspectivas de mundo, de humanização e de aprendizagem que se tornem possíveis no momento atual, às quais o autor contrapõe as perspectivas escolares, por ele denominadas de educação bancária.

No subprojeto Geografia, tanto no Ensino Fundamental como no Ensino Médio, os bolsistas desempenham o mesmo tipo de ação: realizam as atividades nas aulas, participando delas, e, eventualmente, desenvolvem oficinas no contraturno, buscando colaborar com educando e professor. As oficinas e atividades são planejadas pela professora coordenadora do subprojeto e acompanhadas, na escola, pelas professoras supervisoras.

As dinâmicas demonstram ser possível observar que saberes e espaços de formação são articulados por demandas provocadas pelas práticas na escola, bem como emergem dos debates e de leituras realizadas. De todo, é necessário fornecer aos bolsistas espaço para perguntas, questionamentos e autonomia na organização, enfim, criar espaços de diálogo, em que se sintam participantes e integrantes de um processo de ensino/aprendizagem contínuo, permitindo a cada indivíduo compartilhar angústias e anseios, no intuito de possibilitar caminhos a serem trilhados na jornada de educar.

De modo geral, o PIBID/Geografia tem sido uma forma de experienciar novas maneiras de atuação no ambiente escolar, e de verificar sua relevância no avanço da aprendizagem dos educandos envolvidos e, ao mesmo tempo, aproximando a escola da universidade, fazendo com que os bolsistas vivenciem a prática escolar, tornando-os conhecedores de sua prática como professores e, ainda, possibilitando aos professores da educação básica uma continua atualização de saberes e vivências. 


\section{Teoria/Prática - 0 cotidiano}

Muito debatidas em disciplinas do curso de Licenciatura em Geografia, as novas formas de atuar no ambiente escolar foram inferidas mais fortemente quando discutidas novas linguagens no ensino de Geografia. Tais linguagens podem ser desenvolvidas e utilizadas tanto para atividades de reforço como para oficinas ou mesmo para atividades lúdicas. Esse processo requer um contexto articulado e ativo, que permita a igualdade de condições para todos os atores na superação das limitações e ambiguidades do ensino formal.

O que se nota é um grande distanciamento entre as aprendizagens provindas da universidade com as aprendizagens envolvidas na prática da docência na escola. Os dois espaços são diferentes. Todavia, na universidade, há uma intencionalidade de integração da formação, sem dicotomia entre teoria e prática, uma vez que ambas precisam ser refletidas por meio das aprendizagens da docência. Sendo assim, ambas seriam espaços de formação teórico/prática.

Nesse contexto, o trabalho dos bolsistas está pautado na valorização das práticas e trabalhos que já existem na escola, construindo uma integração com o espaço de formação acadêmica. Também desenvolvem a prática a partir da perspectiva dos educandos e dos professores como sujeitos de saberes construindo,, por conseguinte, construindo conhecimento necessário para a educação de século XXI.

A seguir, seguem algumas atividades desenvolvidas pelo PIBID junto às escolas e também atividades realizadas no Seminário Institucional do PIBID da UFSM.

A atividade envolveu educandos do $1 .^{\circ}$ ano do Ensino Médio, cujo objetivo era confeccionar mapas táteis para que eles pudessem reconhecer os continentes por meio da forma, corroborando para formarem mentalmente a imagem do mapa-múndi. Além disso, tinha por objetivo despertar nos educandos a importância da inclusão social, pois aqueles com necessidades especiais precisam de atividades diferenciadas das habituais para que aconteça o processo de ensino aprendizagem. Nesse caso, os mapas táteis funcionam como recursos educativos capazes de facilitar a compreensão da realidade. 
Figura 1: Atividade PIBID/Geografia/UFSM, em 2016. A, B, C e D - Confecção de mapas mundiais táteis com educandos do $1 .{ }^{\circ}$ ano do Ensino Médio
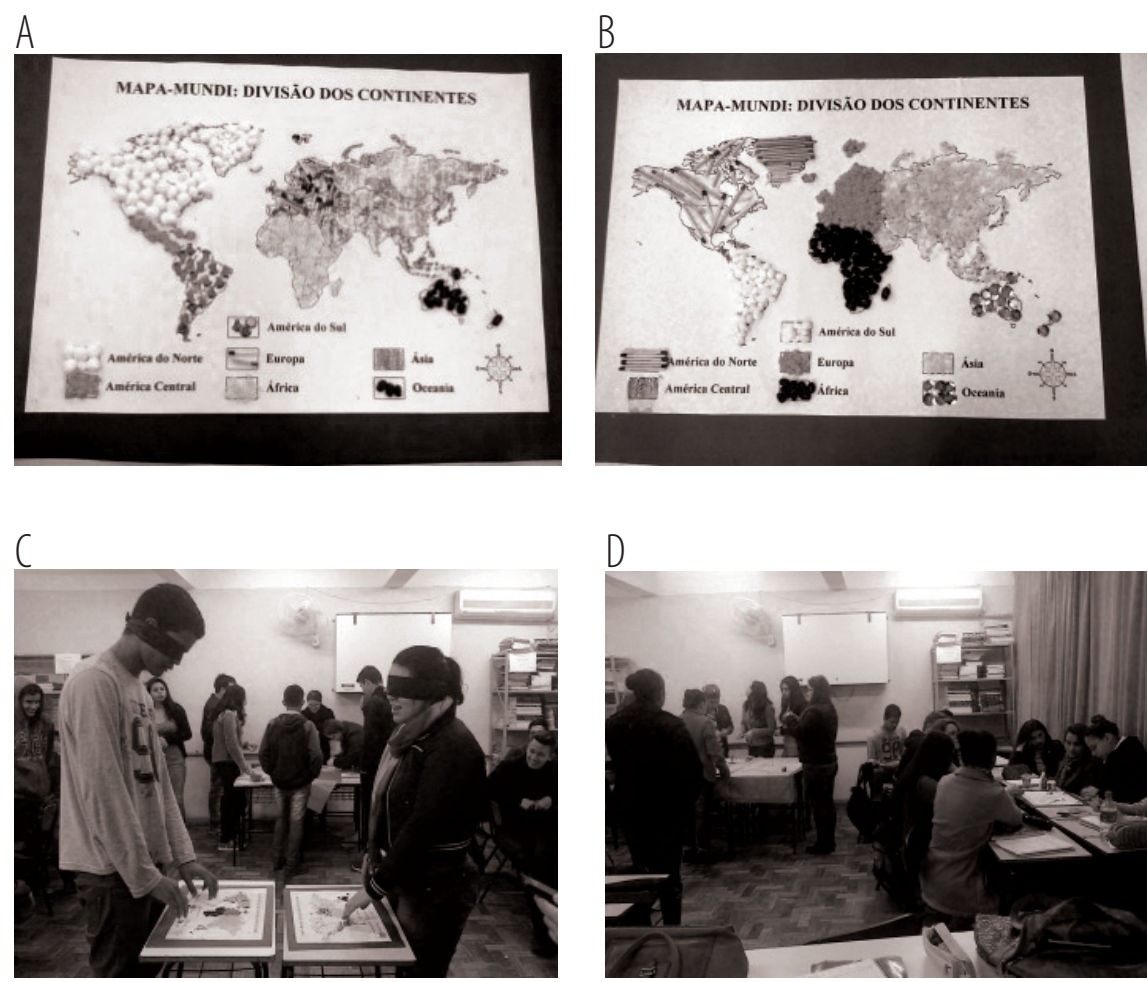

Fonte: arquivo do PIBID/Geografia/UFSM, em 2017.

De acordo com Loch (2008), o uso de mapas permite compreensão geográfica do mundo, facilita a mobilidade espacial e possibilita a ampliação da percepção espacial.

A confecção de maquetes sobre as placas tectônicas, realizada com educandos do $3 .^{\circ}$ ano do Ensino Médio, cujo objetivo foi trabalhar esse conhecimento de forma que os alunos pudessem compreender como o fenômeno acontece na natureza. Para tal, eles confeccionaram maquete, simulando movimento entre os limites divergentes e convergentes das placas tectônicas.

A figura 2 demonstra uma maquete $\mathrm{A}$ e $\mathrm{B}$ das placas tectônicas com alunos do $3 .^{\circ}$ ano do Ensino Médio em 2014; C e D - maquete da cidade de Rio Grande (RS), realizada pelos alunos de $10^{\circ}, 2 .^{\circ}$ e $3 .^{\circ}$ anos do Ensino Médio, em 2014. 
Figura 2: Atividades do PIBID/Geografia/UFSM, em 2014
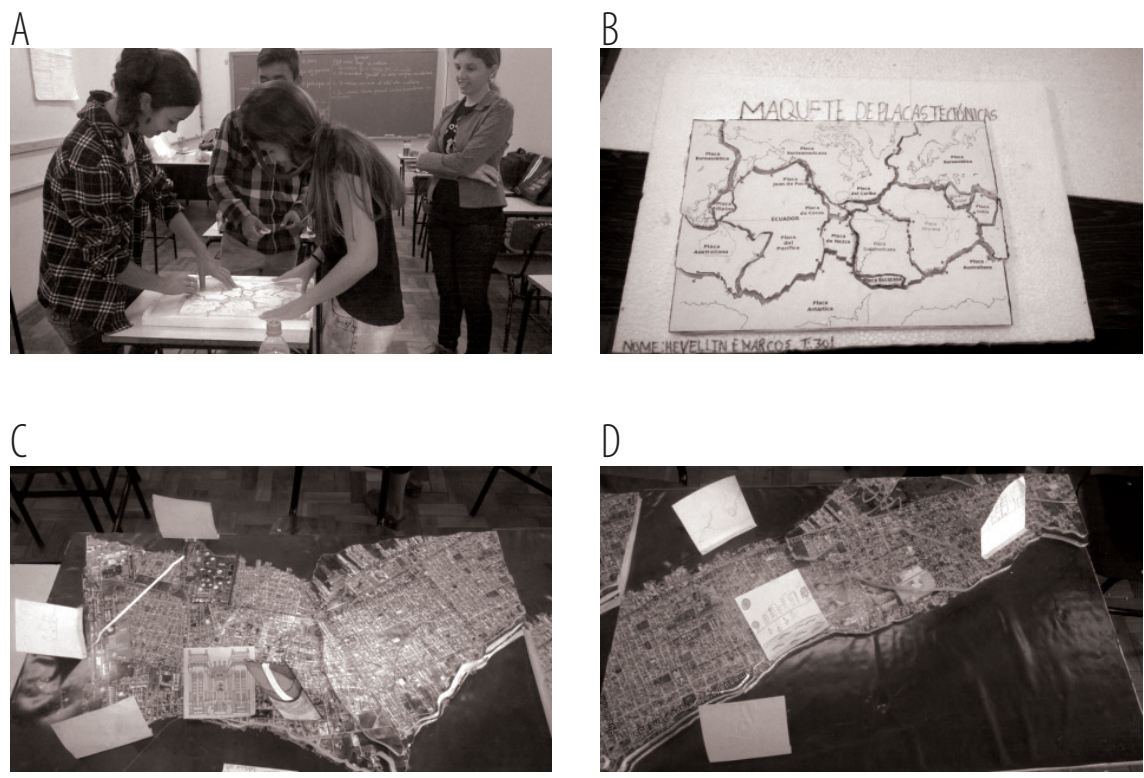

Fonte: Arquivo do PIBID/Geografia/UFSM, em 2017.

A maquete da cidade de Rio Grande (RS) foi confeccionada pelos educandos do Ensino Médio, objetivando a construção de conhecimentos sobre os aspectos físicos, históricos, econômicos da cidade. Esse foi o tema gerador de projetos em todas as áreas de conhecimento, e coube à Geografia representar, cartograficamente, a noção de lugar, uma vez que as diversas linguagens utilizadas para aprendizagem, como a maquete, se tornam fundamentais ao ensino da Geografia por trabalharem tanto a compreensão do espaço geográfico como a realidade vivenciada pelos educandos.

Nesse contexto, Almeida (2001) enfatiza ser o ensino de mapas e de outras formas de representação espacial uma importante tarefa da escola, ou seja, preparar o aluno para compreender a organização da sociedade, a que passa necessidade de conhecimento de técnicas e instrumentos à representação gráfica dessa organização.

A Fígura 3 demonstra, na imagem A, a oficina sobre o mosquito da dengue ministrada no Seminário Institucional do PIBID/UFSM, em 2016; na imagem $B$, a confecção da armadilha do mosquito da dengue e, na imagem C, a participação no Seminário Institucional do PIBID/UFSM, em 2016. 
Figura 3: Atividades do PIBID/Geografia/UFSM, em 2016
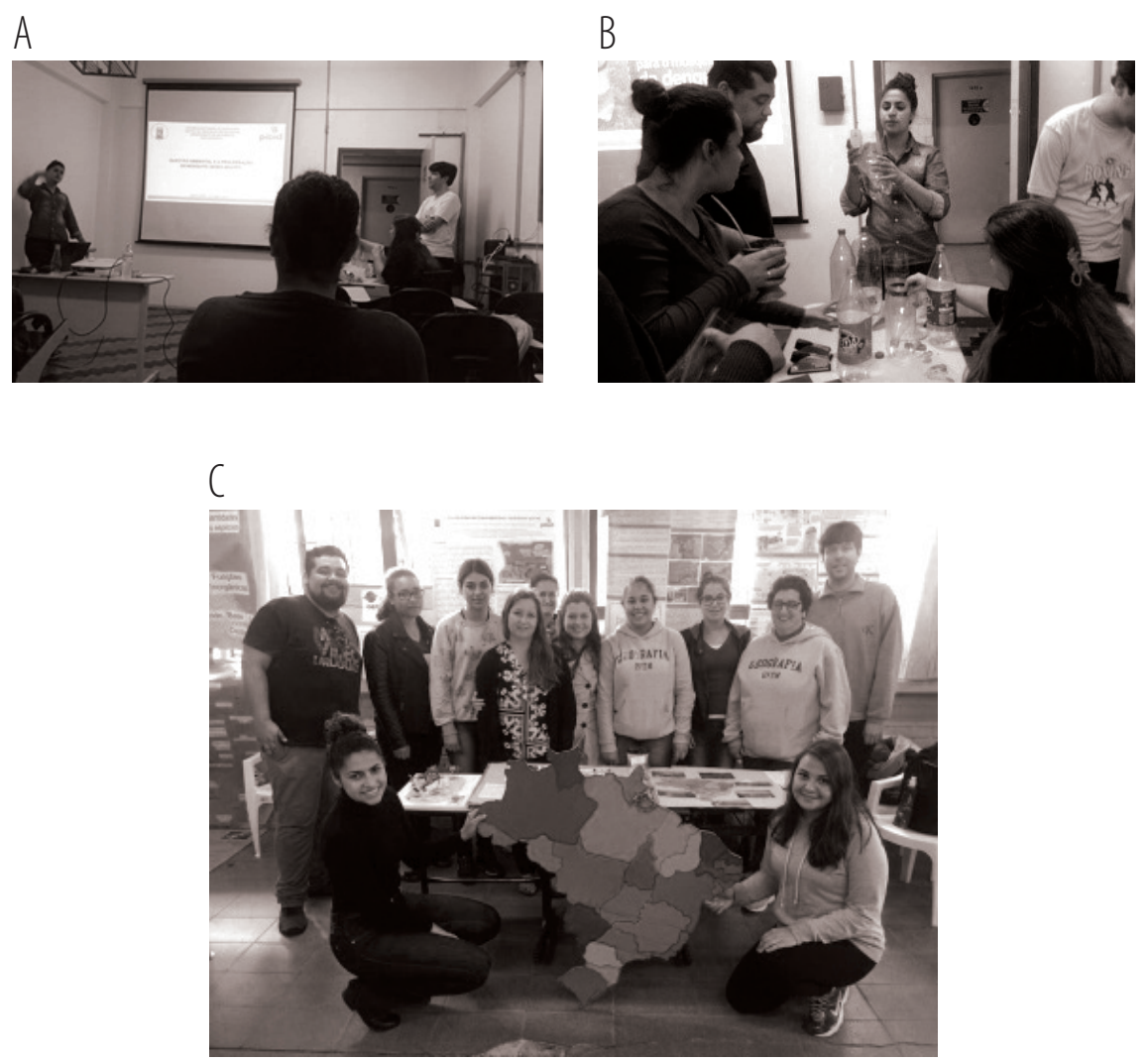

Fonte: Arquivo do PIBID/Geografia/UFSM, em 2017.

O Seminário Institucional do PIBID da Universidade Federal de Santa Maria acontece anualmente e tem por objetivo a troca de experiências e aprendizagens entre os subprojetos. É de responsabilidade de cada subprojeto oferecer uma oficina no seminário, cujo objetivo permite que bolsistas de outros subprojetos interajam com o referido tema e que tais oficinas deem visibilidade aos trabalhos desenvolvidos, como também promovam atividades conjuntas entre os subprojetos. A partir da figura $4-\mathrm{A}, \mathrm{B}, \mathrm{C}$ e D -, visualiza-se a confecção de cidades sustentáveis por educandos do $7 .^{\circ}$ ano do Ensino Fundamental, em 2017. 
Figura 4: Atividade do PIBID/Geografia/UFSM, em 2017
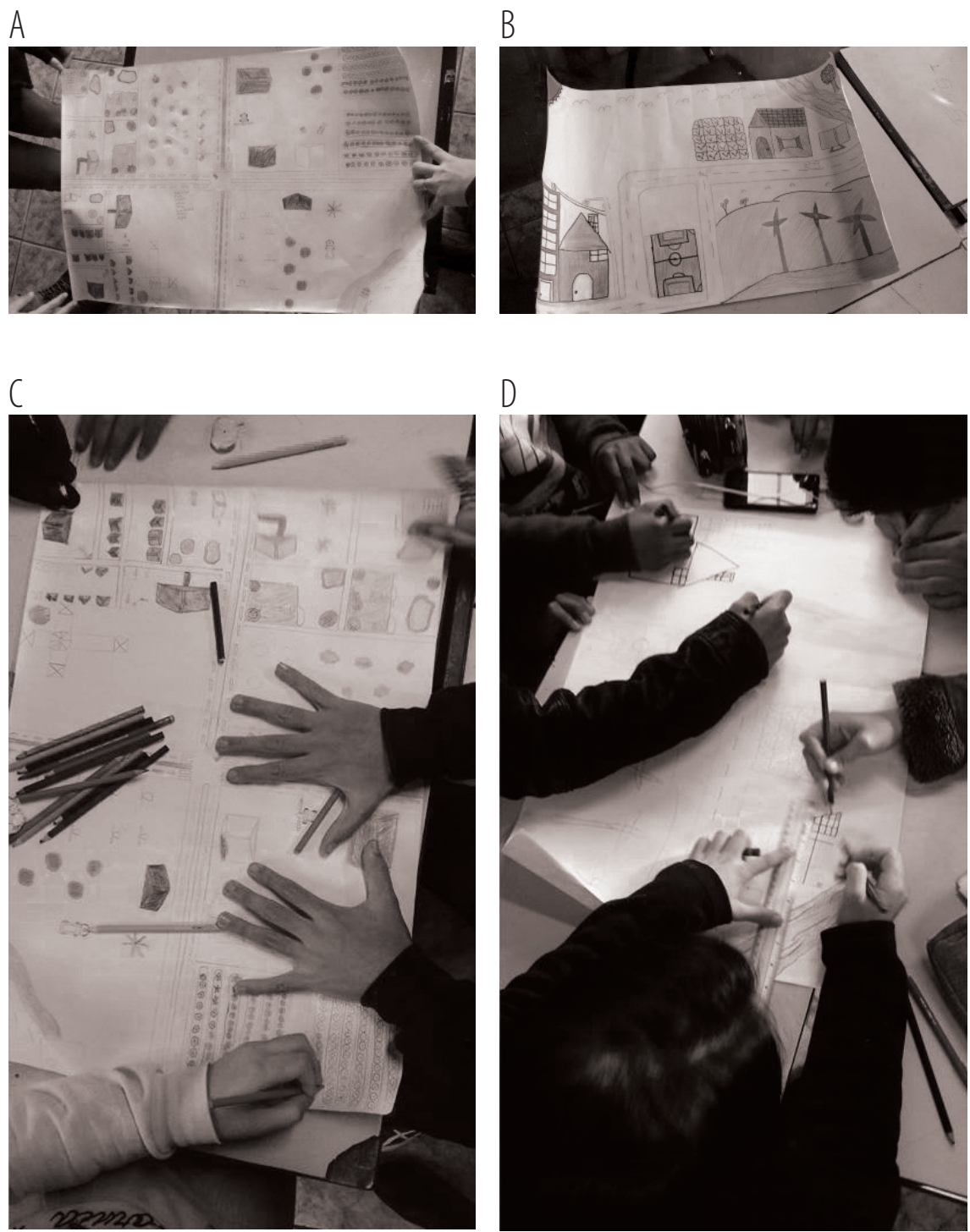

Fonte: Arquivo do PIBID/Geografia/UFSM, em 2017. 
A confecção de cidades sustentáveis foi realizada com os educandos do 7. ${ }^{\circ}$ ano do Ensino Fundamental, objetivando mostrar o padrão de consumo da sociedade atual, que não é sustentável, bem como gerar nos educandos o senso de coletividade e atenção com o ambiente em que vivem.

Os mapas sobre os climas do Brasil foram realizados pelos educandos do 3. ${ }^{\circ}$ ano do Ensino Médio e ilustram a diversidade climática existente no país, sua área de abrangência e características. Tais questões estiveram sempre relacionadas com o tipo de clima no qual o educando está inserido. $\mathrm{Na}$ figura 5, demonstramos, na parte A e B, a confecção de mapas de climas do Brasil por educandos do $3 .^{\circ}$ ano do Ensino Médio, em 2017; nas imagens C e $\mathrm{D}$, a confecção de mapas de refugiados no Brasil, no mesmo ano.

Figura 5: Atividade do PIBID/Geografia/UFSM, em 2017
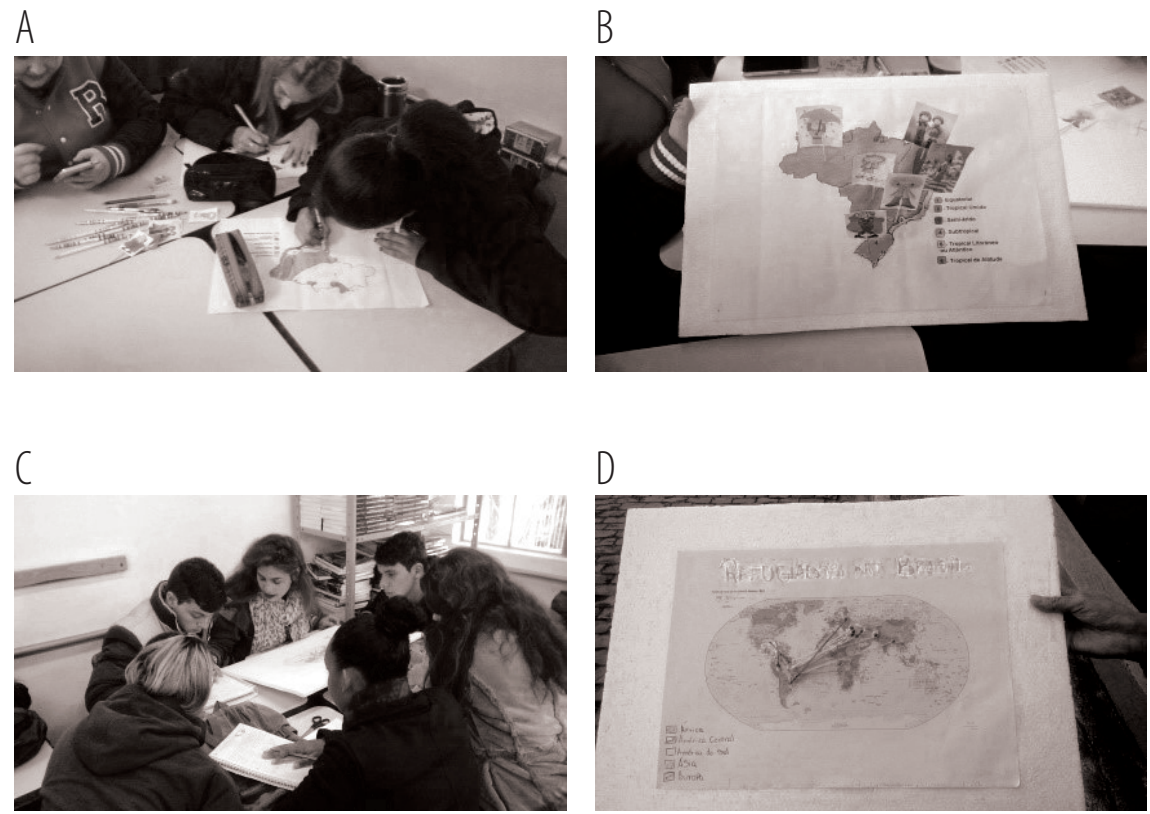

Fonte: Arquivo do PIBID/Geografia/UFSM, em 2017. 
O estudo do processo migratório contemplou a confecção de mapa sobre os refugiados no Brasil, no qual estabeleceram os fluxos existentes tanto para o movimento de imigração como para o de emigração. Isso posto, os educandos foram capazes de criar mecanismos por meio dos quais puderam desenvolver comparações entre o fenômeno mundo x Brasil, tão importante para a compreensão do referido caso.

\section{Desdobramentos da ação do Programa PIBID junto aos antigos acadêmicos do curso de Licenciatura em Geografia da UFSM}

A fim de evidenciar a importância o PIBID também como política pública para a formação docente dos acadêmicos do curso de Licenciatura em Geografia da UFSM, elaborou-se questionário para os antigos bolsistas ${ }^{1}$ do programa. Do total de vinte bolsistas que passaram pelo programa, 13 responderam aos questionários, cujas indagações versaram sobre o tempo de participação no programa, as experiências e conhecimentos da prática pedagógica antes do programa, a importância do PIBID na sua formação, a atuação do bolsista após a participação no programa e a importância do programa para o curso de Licenciatura Plena em Geografia da UFSM.

Em relação à primeira indagação, observa-se, na figura 6, que 54\% dos bolsistas participaram até dois anos no programa, tempo esse estipulado pela Capes, em 2011, como máximo aos alunos de Iniciação à Docência (BID). Participaram por três anos do programa 23\% dos bolsistas, tempo possível porque que não havia limite de participação, e 23\% participaram por um ano, visto que já estavam em fase de finalização do curso de Licenciatura, o que inviabilizou um período maior de inserção junto ao programa.

\footnotetext{
${ }^{1}$ Optou-se somente pelos acadêmicos que já encerraram a participação no programa, em função de serem conhecedores de sua metodologia e de como tal programa contribuiu para sua formação docente.
} 
Figura 6: Tempo de participação dos bolsistas no programa do PIBID/Geografia/UFSM

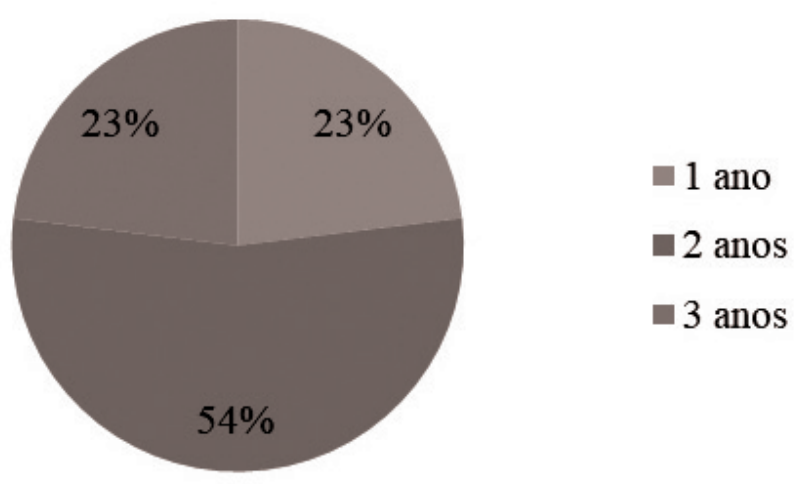

Fonte: Arquivo do PIBID/Geografia/UFSM, em 2017.

Tanto no tempo que foi estipulado pela instituição mantenedora, como no tempo hábil de condição, fica evidente que os bolsistas participaram o máximo permitido pela instituição. Assim, observa-se o interesse dos bolsistas no programa, revelado pelos seus crescentes desenvolvimentos frente à prática pedagógica, bem como pela participação máxima permitida, obedecendo à condição de cada um.

Ao dissertarem sobre os conhecimentos prévios da prática pedagógica antes do programa, fica evidente em todas as falas que não possuíam nenhuma experiência prática na escola. Apenas três bolsistas manifestaram experiência em cursinhos pré-vestibulares ofertados pela própria universidade. Entretanto, ressaltaram que essa experiência é muito diferente da vivenciada na escola pública. Por conseguinte, a maioria, cerca de $76,9 \%$, ressalta que o conhecimento se dava apenas pela teoria contemplada nas disciplinas voltadas à educação ou pela busca individual, por meio de livros que abordam o tema.

Tal preposição mostra que o modo como estão organizados os programas de licenciatura no Brasil, de maneira geral, prioriza o conhecimento teórico em detrimento da prática pedagógica, a qual ocorre apenas no estágio supervisionado, levando o acadêmico a um despreparo quanto à realidade complexa da escola, contribuindo para os altos índices de abandono dos cursos de licenciatura no país. Em função disso, enquanto programa focado na licen- 
ciatura e nas práticas pedagógicas, o PIBID é muito importante na formação docente e na valorização dos cursos de licenciatura como um todo.

No que se refere à importância do PIBID na formação docente dos bolsistas, inferiu-se que o programa possibilitou a aproximação da teoria e da prática, sendo importante para a definição e entendimento do ser professor, proporcionando aprendizados, desde como lecionar, elaborar planos de aula, organizar determinada atividade ou a postura em sala de aula, até enfrentar a realidade complexa escolar, compreender as diferenças entre os níveis de ensino e diferenças de aprendizagens; além disso, contribuiu para o conhecimento da importância da produção acadêmica mediante a produção de trabalhos para apresentação em eventos da área em estudo e também na definição do ensino de Geografia como área de pesquisa e atuação, conforme evidenciado nas seguintes falas:

O PIBID foi fundamental, uma vez que antecipa a experiência docente dentro da academia, que naturalmente ocorre no último ano da graduação. A possibilidade de tempo de planejamento, discussão, elaboração de recursos didáticos, de ações dentro da escola, de reflexão com os colegas bolsistas foram fundamentais para o meu atual exercício docente. Somam-se a esses fatores, ainda, as leituras estimulantes propiciadas por nossa orientadora, que ainda repercutem na nossa sala (Bolsista, 2011-2014).

Foi a partir dele que defini o ensino de Geografia como campo de pesquisa para minha formação continuada e nele tive a certeza que os desafios com a educação são muitos, mas que acertei em definir a educação como campo profissional (Bolsista, 2011-2013).

Os depoimentos revelam que o PIBID ultrapassa seu principal objetivo, que é a inserção dos alunos no contexto escolar, à medida que rompe com os "muros" da escola/universidade e que instiga o aluno a continuar os estudos buscando uma formação para além da graduação. Aproxima os futuros pesquisadores do ensino enquanto campo profissional que, nos últimos anos, vem perdendo interesse em todas as áreas do conhecimento devido à desvalorização da educação no Brasil. Portanto, o programa possibilita o fomento da permanência dos acadêmicos nos cursos de licenciatura e corrobora para que permaneçam nesse campo de pesquisa. 
Outro aspecto que reforça a importância do PIBID para as licenciaturas, em especial a Geografia, é que a maioria dos seus antigos bolsistas está inserida no mercado de trabalho e continua se especializando por meio dos cursos de pós-graduação (figura 7), cujo percentual é de 38\% do total. Os antigos bolsistas, que atuam como professores da educação básica, correspondem a 23\%; os que estão dando sequência aos estudos mediante nos cursos de pós-graduação somam 15\%; os antigos bolsistas que ainda estão se graduando e que estão se preparando para a seleção de pós-graduação e os que atuam em outra área correspondem a $8 \%$ cada um. Dessa maneira, observa-se que apenas uma pequena parcela dos antigos bolsistas não trabalha na área, mostrando ser o programa motivador tanto na formação docente como na preparação e incentivo para que os alunos deem continuidade aos estudos, contribuindo, assim, para sua permanência na Geografia.

Figura 7: Área de atuação dos antigos bolsistas do programa do PIBID/Geografia/UFSM, em 2017

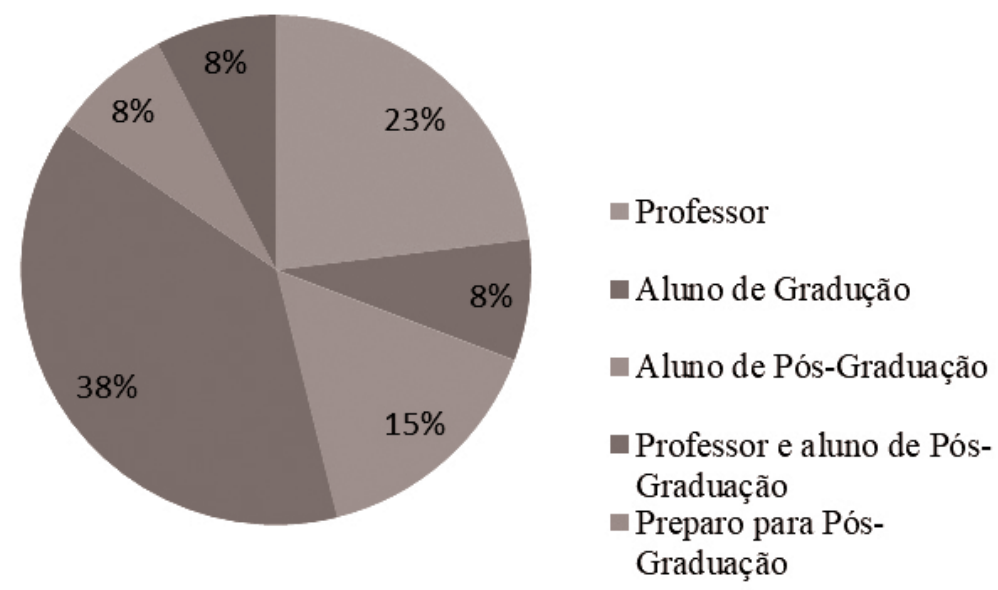

Fonte: Arquivo do PIBID/Geografia/UFSM, em 2017.

Em relação à importância do programa para o curso de Licenciatura Plena em Geografia, foram unânimes em concordar com o importante papel que o programa desempenha junto ao curso, assim como para as demais licenciaturas, conforme mostra o seguinte depoimento: 
O projeto possui enorme relevância para o curso de Licenciatura em Geografia, assim como para os demais cursos de licenciatura. É um projeto que se propõe a experienciar contatos entre futuros professores e a educação básica, proporcionando a prática pedagógica. Acredito que as atividades realizadas trazem experiências benéficas para o discente em fase de formação e o preparam para assumir com responsabilidade seu papel na sociedade (Bolsista, 2014-2016).

Reforçando a amplitude do programa, foram destacados alguns pontos, sendo por intermédio dele que os acadêmicos têm sua primeira inserção na escola, cuja experiência em sala de aula possibilita a pesquisa fundamental na prática docente, promove discussão de anseios e possibilidades com outros licenciados, contribuindo para que se conheça a futura profissão, sanando qualquer dúvida sobre o assunto. A maioria dos antigos bolsistas concorda ser o programa tão relevante que deveria contemplar automaticamente todos os acadêmicos da licenciatura do curso de Geografia.

Além disso, reforçam que o referido programa gerencia a interação escola/universidade, cuja contribuição para uma educação básica de qualidade é notória ao formar educandos conscientes de seu papel transformador na sociedade.

\section{Considerações finais}

O PIBID/Geografia tem representado um espaço de interlocução, de amadurecimento dos estudos educacionais e de solidificação de estudos sobre o cotidiano dos educandos. As reunióes são pontos de encontro de experiência, saberes, dúvidas e conhecimentos, tempo para refletir e discutir a prática pedagógica. Além do conhecimento tecido ao longo do programa, o PIBID/Geografia permite conhecer algumas dinâmicas do âmbito acadêmico e da escola básica, pesquisas que preparam os bolsistas para estudo e experiência docente posteriores. A história desse programa para a melhoria dos cursos de licenciatura evidencia, na fala dos antigos acadêmicos participantes, estrutura pertinente e fundamental para o exercício e aprimoramento da atividade docente, a qual deve estar inserida nos primeiros anos do curso acadêmico. 
A forma como os acadêmicos de graduação se referem aos conhecimentos a eles conferidos indica a possibilidade de integração entre os saberes aprendidos na academia e os saberes aprendidos na escola, apontando a relevância desse programa no âmbito da formação de professores.

\section{Referências}

ALMEIDA, R. D. de. (org.). Do desenho ao mapa: iniciação cartográfica na escola. São Paulo: Contexto, 2001.

CALLAI, H. C. A formação do profissional da geografia: o professor. Ijuí: Editora UNIJUÍ, 2013.

FREIRE, P. Pedagogia do oprimido. São Paulo: Paz e Terra, 1972.

LOCH, R. E. N. “Cartografia tátil: mapas para deficientes visuais”. Portal da Cartografia, v.1, n. 1, 2008. Disponível em: http://www.uel.br/revistas/ uel/index.php/portalcartografia/index. Acesso em: $1^{\circ}$ set. 2017. 